\title{
Comparison of the Effects of Giving Gift and Relational Investment on Reciprocity Likelihood in B2B Context in Taiwan \\ Yu-Chen $\mathrm{CHEN}^{1, \mathrm{a},{ }^{*}, \text { Rong-An SHANG }}{ }^{1, \mathrm{~b}}$, Yu-Jen $\mathrm{CHEN}^{1, \mathrm{c}}$
}

\author{
${ }^{1}$ Department of Business Administration, Soochow University, No 26, Sec. 1, Kuei Yang St., Taipei, \\ Taiwan \\ acyc@scu.edu.tw, ${ }^{\text {b}}$ rashang@scu.edu.tw, ${ }^{c} y u-J e n-C h e n @$ hotmail.com \\ *Corresponding author: Yu-Chen, Chen, Ph.D.,cyc@scu.edu.tw
}

Keywords: Gift, Manipulative Intent, Relational Investment, Mianzi, Value.

\begin{abstract}
External relationships are required for running businesses. While rooting on Western management theories to run their businesses, Taiwanese business managers are also affected by Chinese culture, such as giving gift to maintain other's face during business negotiation. Hence, it is interesting to know and compare the effects of these two conducts on business partners' reciprocity likelihood(RL). A structural model was tested with data collected from 125 questionnaires. The results show that both relational investment(RI) and gifting behavior have positive impacts on RL; yet, giving gift, through the mediation of Mianzi(face), exert a stronger affection on RL than RI.
\end{abstract}

\section{Introduction}

Business can hardly survive without external relationships. Cultivate external relationships with suppliers or partners are required for successfully doing business. Many researches have focused on how to effectively invest in mutual relationship to increase the possibility of reciprocity likelihood(RL)in the future [4;11].In oriental society, it is not an un-common practice to improve the relationship and RL by giving gift to business partners; yet, in western society, giving gift is often considered as bribery. Hence, the effect of giving gift on RL was rarely being examined[e.g., see 18].This study intends to mitigate this gap, and compare the effects of relational investment (RI) and giving gift on RL, in a context of small and medium enterprises in Taiwan.

For some decades, Taiwan's business systems are deeply influenced by and rooted on Western thoughts and knowledge. Yet, their initiatives are also impacted by Chinese cultural values at the same time. Specifically, this study will focus on the roles of Mianzi or face, the perception of one's social status, prestige, or pride [13; 18] and gifting behavior. In social interactione, it is important for Chinese people to conduct face work, like giving someone expensive gifts, to maintain one's own, or other's Mianzi.The objective of this study, hence, is to explore the answer of the question: whether or not gifting and Mianzi should be considered to extend the RI theories to fit in the specific context of Taiwan businesses.

\section{Literature Review and Model Development}

\section{The Antecedents and Consequences of Relational Investment}

Blau [3]defined RI as "an investment of time, effort, and other irrecoverable resources in a relationship creates psychological ties that motivate parties to continue the relationship and sets an expectation of reciprocation." Generally, customers may highly likely be favorably impressed, once a seller makes a relationship investment using bonding tactics of any kind. As Kang andRidgway [14] contend, the recipients may feel a need to reward the marketer's or seller's "friendliness." Moreover, Bagozzi [2]found that customers illustrated loyalty to certain sales representatives in reciprocation of these sales representatives' investments in the relationship. By devoting resources and efforts to relationship investment, sellers, hence, can have strong connections with their customers, which in turn can improve sellers' performance such as increased sales growth, market 
share and profitability [8; 21]. Therefore, hypothesis 1 (H1) is proposed: A higher perceived relationship investment leads to a higher degree of reciprocation likelihood.

De Wulf et al. [10] identified four relationship efforts, including direct mail, preferential treatment, interpersonal communication, and tangible rewards, as determinants of perceived relationship investment. Among those efforts, direct mail and tangible rewards are not deemed appropriate in the business-to-business (B2B) context in which enterprise procurement is different with personal shopping. The remaining two efforts are considered to be appropriate as the antecedents of relationship investment in the B2B context. The effects of the above two variables can be explained by the concept of reciprocity in social exchange behavior. Normally, people feel an ingrained psychological pressure to reciprocate after they received a benefit; Once people fail to repay obligations, it can lead to a feeling of guilt [12; 23]. People should repay good for good, in proportion to what they receive to create stable exchange relationship [2]. Hence, the following hypotheses are proposed: Perceived interpersonal communication and preferential treatment will be positively related with perceived relationship investment (H2, H3).

However, people measure the kindness of action not only by its consequences but also by the intention underlying this action [12]. While giving gifts to customers, businesses may express their intent of future reciprocation, either explicitly or implicitly. While perceiving such intent, people may feel they were being enforced to reciprocate, and the choice of reciprocation is limited to the ways preferred by the businesses, which may cause adverse effects on the perception of RI, or even hurt buyers' intent to reciprocate[4].Accordingly, hypothesis $4(\mathrm{H} 4)$ is proposed: A higher level of perceived gift manipulation leads to a lower level of perceived relationship investment.

\section{Giving Gift and Giving Mianzi}

\section{Gifting Behavior}

Business gift is a gift that a sales representative gives to people in buyers' organizations who own decision power at certain business occasions. Through gift-giving, people show their respects and apologies to other people, or reinforce mutual trust in, caring with and commitment toother parties [9].It is a form of non-verbal and symbolic communication during personal interactions to deliver a variety of messages; and has become usual to a large extent [5].Business gifts are given in the hopes of creating a positive first impression to create an initial business relationship, or expecting a favor in return [1].When people get paid, they may feel obligated to reciprocate [5] and decide to pay back in the future [16;22]. Wolfinbarger and Yale [26]Suggest that people may be motivated to give gift due to a sense of obligation derived from reciprocation purpose.In B2B context, therefore, gift giving to the buyers may allow the opportunity to ask a favor in business deals in the future; suppliers can, through mutual reciprocity, establish and enhance long-term relationships with their customers.

\section{Values of Gift}

Gifts are mostly also ordinary products or services that can be consumed. Hence, a perception of gift value will be derived after its consumption. Consumer value, or consumption value, is defined as an "overall assessment of the utility of a product based on the perceptions of what is received and what is given" [54, p.14]. Price is the primary monetary sacrifice that people paid to get the utility of a product; a higher price normally indicates a higher level of value. In most occasions, gift with higher monetary value are, hence, evaluated more favorably [17; 4].

Since gift is also a medium conveying symbolic meanings, how will the recipient interpret the implications of a gift may have significant influences on the subjective gift consumption experiences. For example, sending a clock or watch may be interpreted as a curse of death and is deemed as inappropriate in Taiwan. A gift of relatively low monetary value can be evaluated advantageously if it is ideal to the recipient, or if it conveys a positive symbol [4]. 


\section{Mianzi}

Western enterprises mostly follow the social exchange rules to establish partnership to fit the business purposes. In opposition, Chinese businessmen, while building partnerships, deeply concerned about and are influenced by traditional cultural variables. Miazi is one of the traditional Chinese cultural variables tied tightly with gift. Mianzi, or face, refers to "an individual's prestige in society, a reputation achieved through getting on in life, through achieving success, and through ostentation [18]." In ethnic Chinese society, mianzi is an individual's possession of the respect, pride, and dignity [13], which is somewhat similar with the Western concept of reputation or dignity [7]. Mianzi can also be defined as one's position in a social network, and the proper implementation of appropriate behaviors to get this respect status as determined by others in the social network.

A social skill named face work was used frequently in Chinese society for people to maintain or improve others' mianzi[15]. Maintaining the mianzi can be described as a protection of one's image in a relational situation, and practice of face work has strong impacts on business decisions [6; 25]. The concern of mianzi may lead to the consumption of luxury goods without necessity [27]. Mianzi is consistently a key factor during professional interactions in Hong Kong[27]. Fear of losing face forms part of the informal system of contracts or agreements in Chinese business. Giving mianzi to someone in a business negotiation is considered highly desirable, and vice versa [19]. Accordingly, hypothesis 5 (H5) is proposed: Mianziis positively associated with perceived reciprocation likelihood.

Since gift can also convey important symbolic meanings highlighting the recipients' face, an inappropriate gift will make the recipients' losing mianzi. One may improve others' mianzi by giving an expensive gift or one being favorably evaluated by the recipient. Conversely, Leung et al. [18] suggested that people can create relationship with one who just met by improving his/ her face through giving appropriate gifts. Hence, the following hypotheses are proposed: A higher gift economic value and preferable evaluation of gift leads to a higher level of mianzi(H6, H7).

\section{Research method}

A theoretical model and a set of hypotheses were developed according to the literature reviewed. The model was composed of two subsets of hypotheses. The first one depicts the role and the antecedents of relational investment $(\mathrm{H} 1-\mathrm{H} 4)$; and the second one describes the role of gift and Mianzi(H5- H7).

This study conducted a questionnaire survey to collect data for hypotheses testing. In order to ensure the content and face validity, all questionnaire items were adapted from existing questionnaire. Among them, scales of interpersonal communication (IC), preferential treatment (PT), and relational investment were adapted from the scales developed by De Wulf et al. [10]; scales of perceived gift manipulation (PM) and reciprocation likelihood (RL) were adapted from those designed by Bodur and Grohmann [4]; subjective gift evaluation (GE) was measured by the scale developed by Mano and Oliver [20]; finally, this study designed the scale of mianzi(MZ) and economic value of gift (GV).

Eight volunteer subjects who have frequent contacts with sale representatives were invited to participate in the pretest. The questionnaire items were being revised according to the subjects' advices. A pilot test with 131informants was conducted to evaluate the quality of the measurement model. Exploratory factor analysis (EFA) was used to evaluate and improve the quality of the measurement model. Seven factors with eigenvalues value larger than one were extracted. According to the results of EFA, PT1 and RL1 were dropped. Snow-ball rolling method was used to collect data. A free online survey platform, My Survey online, was deployed to collect data.

\section{Data Analysis}

A total of 152 samples were collected, and 125 valid samples are left for hypotheses testing. Data 
will be analyzed by Partial Least Square (PLS), and Smart PLS 2.0 will be employed as the primary tool for data analysis (Ringle, C.M., Wende, S., and Will, S., Smart PLS 2.0 [M3] Beta, Hamburg 2005, http://www.smartpls.de). Exploratory factor analysis and Cronbach's $\alpha$ were first used to evaluate and improve the reliability and validity of our measurement model. A principal components analysis with orthogonal rotation by varimax method was conducted. Seven factors with eigenvalues value larger than one were extracted. According to the results of EFA, only one item, MZ3, was dropped, because it has a factor loading less than 0.5 . The variables' Cronbach's $\alpha$ values are all greater than 0.7 , with a highest value of $0.942(\mathrm{RL})$, and a lowest value of $0.818(\mathrm{IC})$.The item loadings are all significant and larger than 0.5; the average variance extracted (AVE) of the variables are all larger than 0.5 ; the composite reliability of the variables are all greater than 0.7 , indicating a satisfactory level of convergent validity. Finally, all the square roots of AVEs were larger than the correlations between any two variables, providing evidence of discriminate validity for the measurements.

Results of the hypotheses testing, shown in table1, show that the independent variables explain $30.2 \%$ of the variance in the reciprocity likelihood construct, and $53.9 \%$ of the variance in the relational investment construct, and $30.4 \%$ of the variance in the Mianzi construct. All the t-statistics of every path are significant. However, the direction of coefficients of the path between PM and RI is contradictory to the predictions of H4. Therefore, this hypothesis is rejected.

Table 1. Summary of the results of hypotheses testing

\begin{tabular}{|c|c|c|c|c|}
\hline No & Hypothesis & Path $(\mathrm{t})$ & Support & Variance explained \\
\hline H1 & RI $\rightarrow$ RL & $0.260\left(4.188^{* * *}\right)$ & Yes & $30.2 \%$ \\
\hline H2 & IC $\rightarrow$ RI & $0.604\left(9.557^{* * *}\right)$ & Yes & $53.9 \%$ \\
\hline H3 & PT $\rightarrow$ RI & $0.142\left(2.008^{* * *}\right)$ & Yes & \\
\hline H4 & PM $\rightarrow$ RI & $0.204\left(4.892^{* * *}\right)$ & No & \\
\hline H5 & MZ $\rightarrow$ RL & $0.43\left(6.855^{* * *}\right)$ & Yes & $30.4 \%$ \\
\hline H6 & GV $\rightarrow$ MZ & $0.227\left(4.689^{* * *}\right)$ & Yes & \\
\hline H7 & GE $\rightarrow$ MZ & $0.420\left(9.988^{* * *}\right)$ & Yes & \\
\hline
\end{tabular}

\section{Conclusion}

The results show that the reciprocity likelihood is influenced positively and concurrently by both relational investment and Mianzi. The subset of hypotheses of Western perspective (H1, H2, H3), and subset of hypotheses of Chinese cultural perspective (H5, H7, H8) are mostly supported. It is worthy and interesting to note that Mianzi exerts a stronger impact than relational investment does, indicating that the decisions of Taiwanese mangers are still being bound by traditional cultural factors. It is advised and suggested by the finding that future studies regarding the theories of relational investment should incorporate the concepts of gift and Mianzi to extend its scope of domain into Eastern society.

Yet, our guess that perceived manipulative intent will decrease the perception of relational investment is not true. Hence, $\mathrm{H} 4$ is rejected. Ordinary consumers may have the freedoms of, and abundant choices. The actions of restricting consumers' spaces of choices by sending a gift may be viewed as urging more for a favor in the short term, rather than concentrating on building relationships in the long run. Conversely, mutual benefits can be gained from the tightened cooperative relations between business partners. A strong and obvious manipulative intent could be interpreted as having an attitude towards building such relationships. 


\section{Reference}

[1] W. Arunthanes, P. Tansuhaj, D.J. Lemak, Cross-cultural business gift giving: A new conceptualization and theoretical framework, International marketing review, 4 (1994) 44-55.

[2] R. P. Bagozzi, Reflections on relationship marketing in consumer markets, J. of the Academy of Marketing Sci., 23 (1995) 272-277.

[3] P.M. Blau, Exchange and Power in Social Life, Transaction Publishers, 1964.

[4] H.O. Bodur, B. Grohmann, Consumer responses to gift receipt in business - to - consumer contexts, Psych.\& Marketing, 22(5) (2005) 441-456.

[5] M. Bruhn, Business gifts: A form of non-verbal and symbolic communication, Euro, Management J., 14(1) (1996) 61-68.

[6] P.J. Buckley, J. Clegg, H. Tan, Cultural awareness in knowledge transfer to China-The role of guanxi and mianzi, J. of World Busi., 41(3)(2006) 275-288.

[7] A.K. Chan, L. Denton, A.S. Tsang, The art of gift giving in China, Business Horizons, 46(4)(2003) 47-52.

[8] L.A. Crosby, K.R. Evans, D. Cowles, Relationship quality in services selling: An interpersonal influence perspective,J. of Marketing, (1990) 68-81.

[9] C. D’Souza,. An inference of gift-giving within Asian business culture, Asia Pacific J. of Marketing and Logistics, 15(1/2) (2003) 27-38.

[10] K. De Wulf, G. Odekerken-Schröder, D. Iacobucci, Investments in consumer relationships: A cross-country and cross-industry exploration, J. of Marketing, (2001)33-50.

[11] M. J. Dorsch, S.W. Kelley, An investigation into the intentions of purchasing executives to reciprocate vendor gifts, J. of the Academy of Marketing Sci., 22(4) (1994) 315-327.

[12] A. Falk, U. Fischbacher, A theory of reciprocity, Games and Eco. Beh., 54(2) (2006) 293-315.

[13] E. Goffman, On face-work: An analysis of ritual elements in social interaction, Psychiatry: J. for the Study of Interpersonal Processes, (1955).

[14] Y.-S. Kang, N.M. Ridgway, The importance of consumer market interactions as a form of social support for elderly consumers, Journal of Public Policy \& Marketing, (1996) 108-117.

[15] Y.K. King, Chinese society and culture. Oxford University Press, HongKong, (1993)(in Chinese).

[16] J.J. LaGaipa, Interpersonal attraction and social exchange, Theory and Practice in Interpersonal Attraction, (1977) 129-164.

[17] D. Larsen, J.J. Watson, A guide map to the terrain of gift value, Psychology \& Marketing, 18(8)(2001) 889-906.

[18] T. Leung, R.Y.K. Chan, K.H. Lai, E.W. Ngai, An examination of the influence of guanxi and xinyong (utilization of personal trust) on negotiation outcome in China: An old friend approach, Industrial Marketing Management, 40(7)(2011) 1193-1205.

[19] Y. Luo, Y. Liu, J. Xue, Relationship investment and channel performance: An analysis of mediating forces,J. of Management Studies 46(7) (2009) 1113-1137.

[20] H. Mano, R.L. Oliver, Assessing the dimensionality and structure of the consumption experience: Evaluation, feeling, and satisfaction, J. of Consu. Res., (1993) 451-466. 
[21] R.M. Morgan, S.D. Hunt, The commitment-trust theory of relationship marketing,The J. of Marketing,(1994) 20-38.

[22] F.I. Nye, Choice, exchange, and the family, Contemporary Theories about the Family, 2 (1979) $1-41$.

[23] R.W. Palmatier, C.B. Jarvis, J.R. Bechkoff, F.R. Kardes, The role of customer gratitude in relationship marketing, J. of Marketing, 73(5) (2009) 1-18.

[24] S.G. Redeling, M. Ng, The role of 'face'in the organizational perceptions of Chinese managers, Org.Stu., 3(3)(1982) 201-219.

[25] S. Ting-Toomey, A face negotiation theory, Theory and Intercultural Communication,(1988) 47-92.

[26] M.F. Wolfinbarger, L.J. Yale, Three motivations for interpersonal gift giving: Experiential, obligated and practical motivations. Advances in Consumer Research, 20(1)(1993) 520-526.

[27] V.A. Zeithaml, Consumer perceptions of price, quality, and value: A means-end model and synthesis of evidence, J. of Marketing, 52 (July) (1988) 2-22. 